THE KURUME MEDICAL JOURNAL

1976 Vol.23, No.3, p.151-161

\title{
THE RESULTS OF CONSERVATIVE TREATMENT OF CONGENITAL DISLOCATION OF THE HIP IN INFANCY
}

\author{
TETSUKO OKUNO \\ Department of Orthopedic Surgery, Kurume University School \\ of Medicine, Kurume, 830, Japan
}

(Received for publication September 25, 1976)

\begin{abstract}
A follow-up study of 184 cases of congenital dislocation of the hip in infancy treated by three different methods, i. e., 44 cases by the Lorenz method ; 67 cases by the method of the abducter splint; 73 cases by the Pavlik method was reported. As the result of this study the following conclusions were reached:

1. Pavlik's functional treatment is excellent compared with another treatments.

2. The hip treated well by the Pavlik splint has not only been led to spontaneous reduction but stimulated to develop the joint normally.

3. The incidence of avascular necrosis was highest in 3 month-oldinfant treated by the abducter splint, while it does not occur in the same aged infant in the Pavlik splint.

4. It is reasonable to presume that the immobilization and the tight abducter muscles in full abduction cause avascular necrosis.

5. The Pavlik splint should be applied rightly and loosely, then avascular necrosis following reduction of congenital dislocation of the hip will not occur.
\end{abstract}

\section{INTRODUCTION}

The femoral head is immature and largely preosseous cartilage during the first year of life. This is a period during which closed reduction of congenital dislocation of the hip is done easily but the femoral head is most vulnerable.

Avascular necrosis of the femoral head following reduction of congenital dislocation of the hip is a serious complication and if it occurs, it leads to deformities of the head and neck of the femur. The incidence of avascular necrosis of the hip in congenital disloca- tion treated by the Lorenz method was high and for which satisfactory results could not be obtained.

Lange reported in 1929 on the result of a follow-up study of congenital dislocation of the hip in the Lorenz method, the anatomical healing could be obtained only in 63.7 per cent of the cases for the period from 1915 to 1925. Fig. 1 shows serious avascular necrosis affecting the both hips after manipulative reduction and immobilization in the Lorenz position of congenital dislocation of the hip.

In 1949 Becker attempted Becker's 


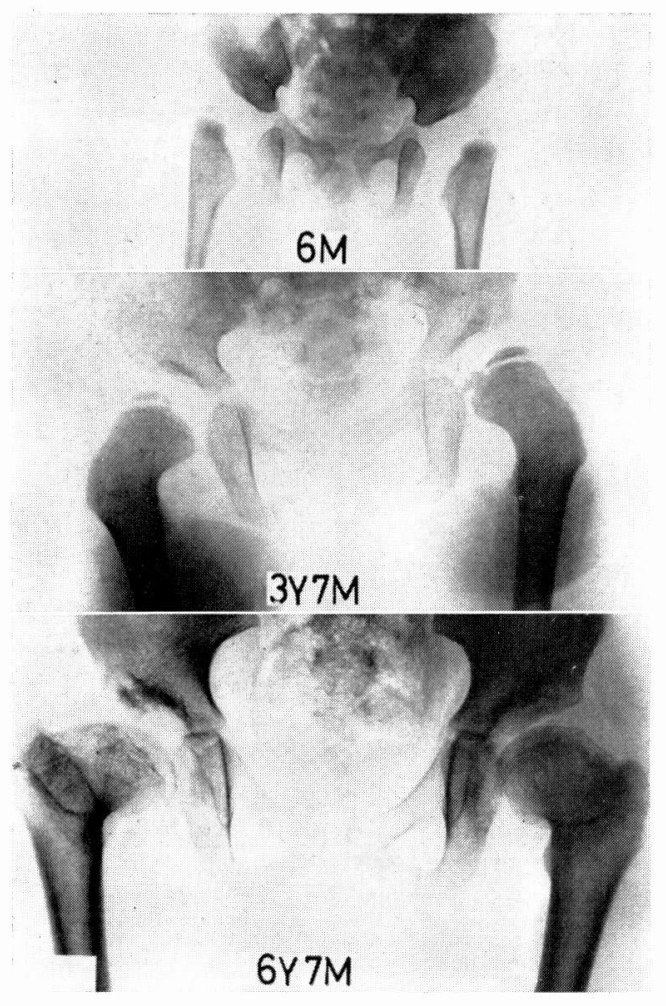

Fig. 1 A boy, six months old with bilateral congenital dislocation of the hip. The patient was treated by manual reduction and immobilization in the Lorenz plaster cast for five months. Fragmentation of the femoral epiphysis at the age of 3 years and 7 months. The fragmentation resulted in deformed head and neck bilaterally.

abductor splint in infants but anatomical healing was obtained in 81.6 per cent of total cases and only in 49 per cent of dislocated cases.

Whereas Pavlik in 1958 reported that spontaneous reduction was obtained (84. 08 per cent) in 531 hips of 631 congenital dislocated hips at the first year of life treated with Pavlik's splint and the incidence of avascular necrosis was 0 per cent. He used of a belt-splint and allowed the patients to exercise all active movements of the lower extremi- ties except the extension of the hips. No such functional and successful treatment had ever been reported in the world. It was first Suzuki (1961) who demonstrated the superiority of the Pavlik method in Japan. Since 1967 we have come to adopt the Pavlik method as treatment of congenital dislocation of the hip in infants.

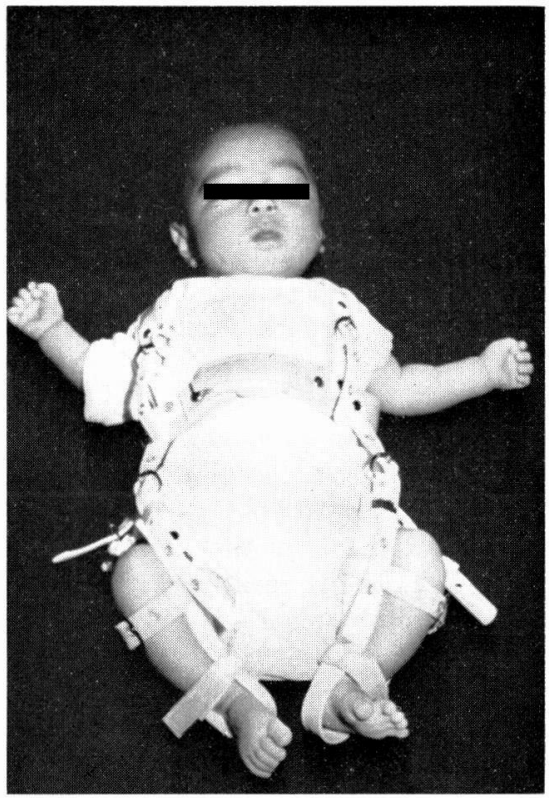

Fig. 2

In this method a patient is made to wear a splint so-called "Riemenbügel" in the hips and knees in 90 degrees of flexion (Fig. 2). Usually spontaneous reduction is obtained in a week or two and the splint is applied for three or four months after reduction and then the patient allows free. The hip joint reduced by the Pavlik method develops proceeding normally (Figs. 3 and 4).

The main object of this study is to examine the superiority of this functional treatment compared with the Lorenz method and the abducter splint 


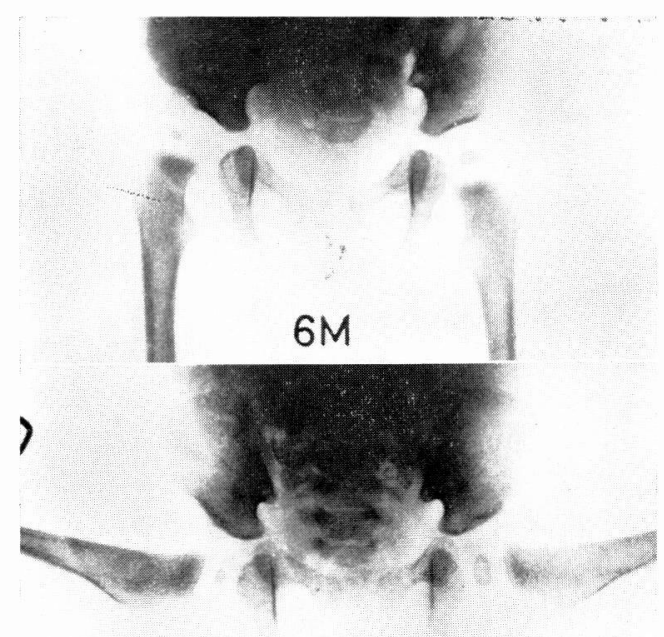

R. B. 1 W.

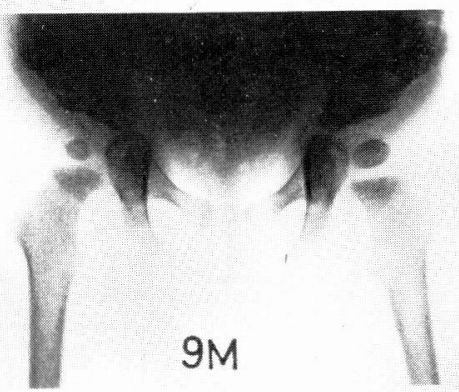

Fig. 3 Congenital dislocation of the right hip at the age of 6 months. A week after wearing the Palvik splint, spontaneous reduction was done. 3 months after reduction the splint was removed and the head became well centered.

which had been used before 1967. And the results of treatment by the Pavlik method with a follow-up of over five years were examined.

\section{MATERIAL}

The study was confined to the patients whose initial treatment was at under the age of one year, reduction was attemped at our orthopedic department and following up for at least ten years except the Pavlik method. Besides
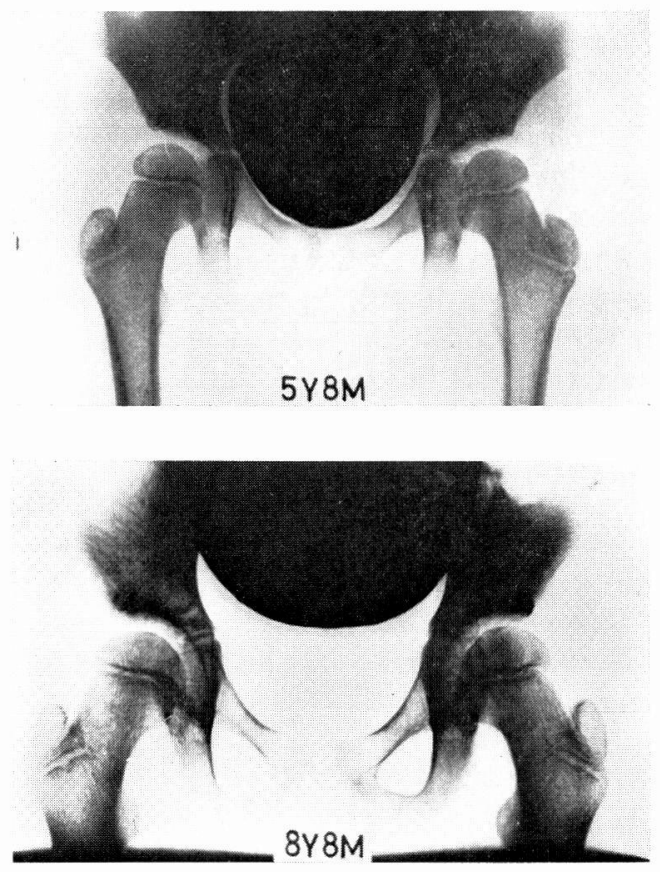

Fig. 4 The same patient at the age of 5 years and 8 years. The hip developed normally.

these were not included a group of patients in whom initial reduction was not successful, a group in whom the dislocation associated with arthrogryposis multiplex congenita, or arthrochalasis, and a group for whom the first radiographs and early results were not available.

\section{GENERAL FEATURES}

\section{The Lorenz method}

There were bilateral in 11 patients and unilateral in 22 patients making a total 44 cases involved 37 cases with dislocation and 7 cases with subluxation. The period of follow-up varied between 10 and 17 years, with an average of 11.3 years. The mean time of fixation was 4 months. 


\section{The abducter splint}

There were bilateral in 23 patients and unilateral 21 patients, 49 of 67 cases were dislocations and the others 18 subluxations.

The mean time of wearing the splint was 2.5 months and the period of followup ranged from 10 to 16 years, with an average of 12 years.

\section{The Pavlik method}

There were bilateral in 16 patients and unilateral in 41 patients involving 54 cases with dislocation and 19 cases with subluxation. The mean time of wearing the Pavlik splint was 3.8 months. These cases were followed-up from 5 to 9 years, with an average of 6.1 years.

\section{ASSESSMENT OF RESULTS}

\section{Early results}

The early results were assessed by the incidence of avascular necrosis, that is epiphysitis. Table 1 shows the number of cases attending for treatment at each month and the incidence of avascular necrosis. Literature dealing with the incidence of avascular necrosis following the abducter splint and the Lorenz method under the age of one year is rare.

TABLE 1

\begin{tabular}{|c|c|c|c|c|c|c|}
\hline \multirow{2}{*}{$\begin{array}{l}\text { Treatment } \\
\text { Month }\end{array}$} & \multicolumn{2}{|c|}{ Lornze method } & \multicolumn{2}{|c|}{ Abducter splint } & \multicolumn{2}{|c|}{ Pavlik splint } \\
\hline & Cases & Necrosis & Cases & Necrosis & Cases & Necrosis \\
\hline 1 & & & & & 2 & 0 \\
\hline 2 & 6. & 0 & 2 & 0 & 4 & 0 \\
\hline 3 & 6 & 2 & 22 & 11 & 14 & 0 \\
\hline 4 & 10 & 2 & 10 & 3 & 20 & 2 \\
\hline 5 & 5 & 3 & 19 & 6 & 15 & 0 \\
\hline 6 & 4 & 2 & 6 & 1 & 6 & 1 \\
\hline 7 & 3 & 2 & 3 & 0 & 10 & 1 \\
\hline 8 & 2 & 0 & 1 & 0 & & \\
\hline 9 & 1 & 0 & 1 & 0 & & \\
\hline 10 & 3 & 1 & 3 & 1 & 2 & 0 \\
\hline 11 & 4 & 0 & & & & \\
\hline Total & 44 & $\begin{array}{c}12 \\
(27.27 \text { per cent })\end{array}$ & 67 & $\begin{array}{c}22 \\
(32.84 \text { per cent })\end{array}$ & 73 & $\begin{array}{c}4 \\
(5.48 \text { per cent) }\end{array}$ \\
\hline
\end{tabular}

It can be seen in this table that the incidence of avascular necrosis is extremely high in Lorenz's group and abducter splint's group especially it is the highest ( 50 per cent) in 3 months of the abducter splint. This fact is not in accord with results by Senju (1960).
She reported that there is not a direct correlation between the time of starting treatment and the results of conservative treatment in infancy. In my data the incidence of avascular necrosis is higher in the cases under the age of 6 months of the abducter splint. 


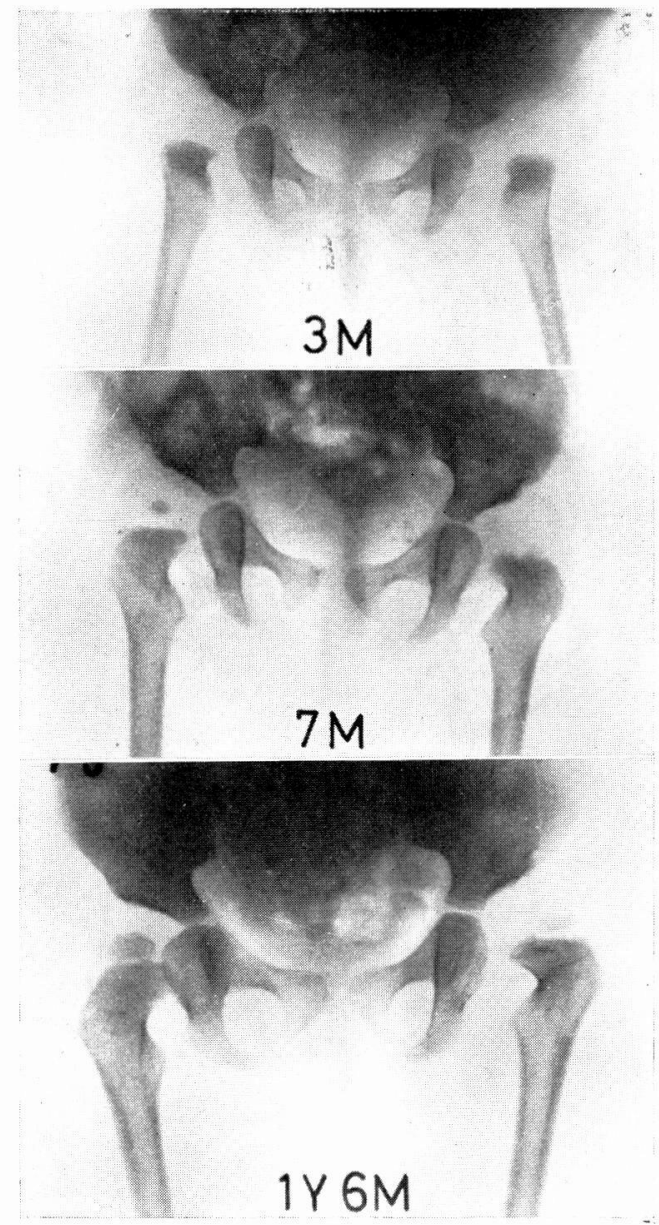

Fig. 5 A girl 3 months old, with bilateral dislocation. Metaphyseal changes present in the left hip 4 months after reduction. The changes are more advance after 11 months.

Furthermore my results are of interest in two ways. First, avascular necrosis more occurs by the abducter splint without manipulation than the Lorenz method. Second, the cases of avascular necrosis treated with the abducter splint are characterized by injury of the metaphysis (Figs. 5 and 6).

According to Becker, the leverage acts on the hip in the narrow abducter splint. Tucker (1949) described that the

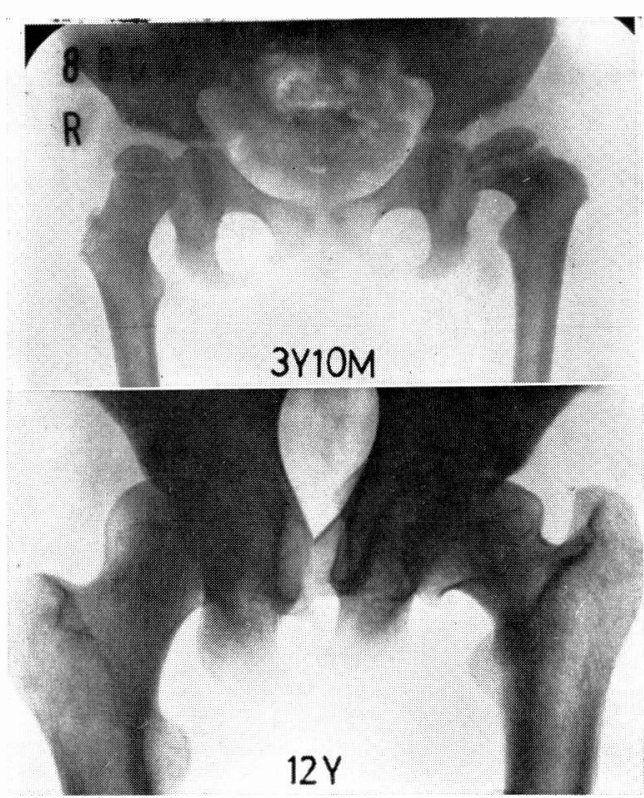

Fig. 6 The same patient at the age of 3 years and 12 years. The right hip shows almost normal state, while the left hip shows a remarkably short femoral neck.

fragmentation of the femoral head caused by full abduction of the hip rather than by manipulation and the degree of pressure on the vessels depended upon the degree of abduction. Against it, Lagrange (1962) observed that vascularization of the femoral head did not deminish in the Lorenz position. So he presumed violent reduction and pressure on the femoral head against the acetabulum caused avascularization. According to Salter (1969) frequent use of continuous traction and adductor tenotomy reduced the incidence of avas cular necrosis from 30 to 15 per cent, furthermore it declined to approximately 5 per cent in the "human" position. In this position the hips are in marked flexion but only slight abduction. Gage (1972) succeeded in diminishing avascular necrosis by such a method as Salter. 


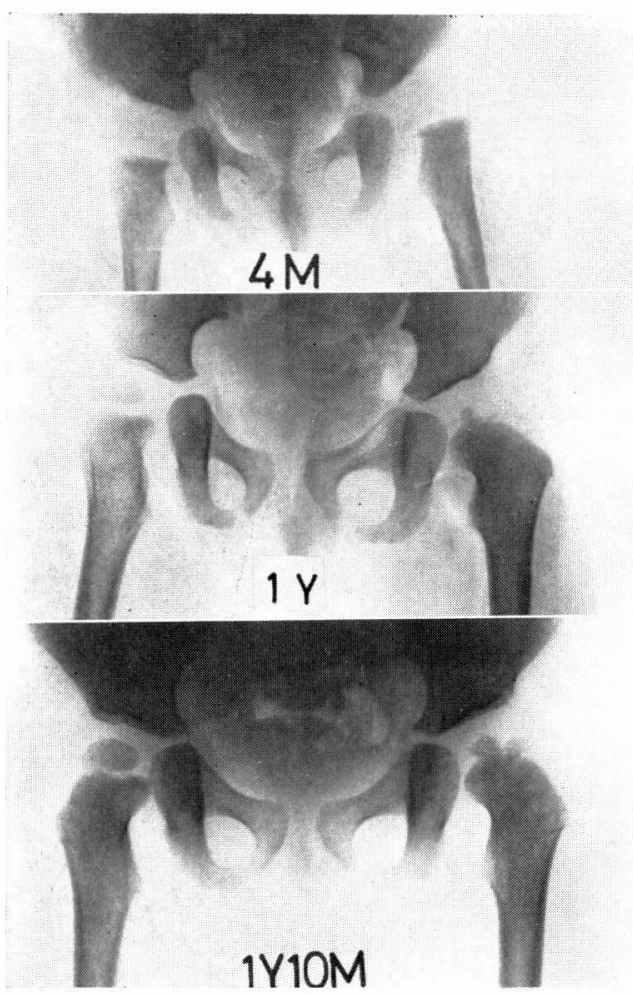

Fig. 7 Congenital dislocation of the left hip. The patient was treated by the Pavlik splint at the age of four months. Spontaneous reduction was obtained in a week and the splint applied for five months. At the age of one year, epiphysitis was more visible.

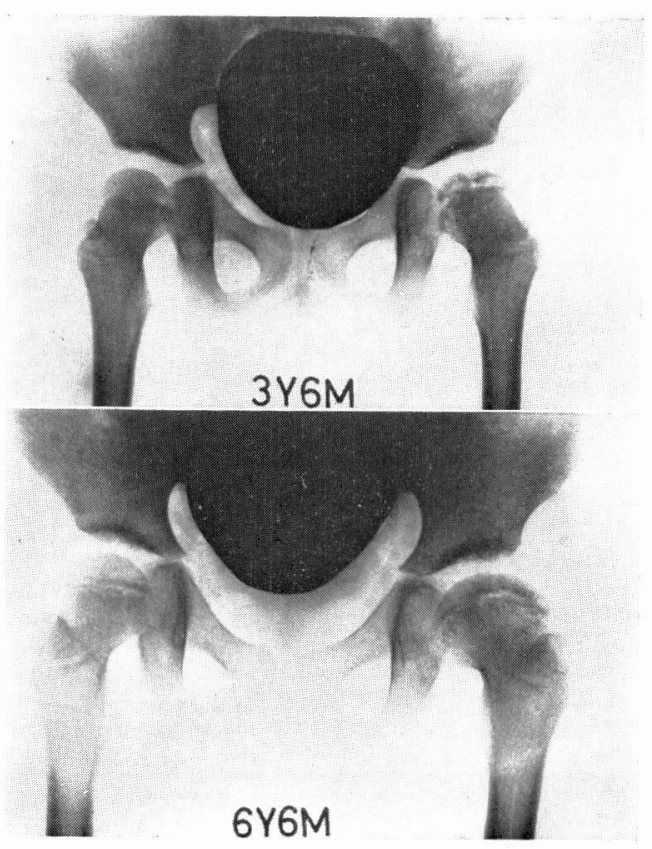

Fig. 8 The appearances at the age of three and a half years. The flattend head was present. The appearances three years later show Coxa plana and slight Coxa magna.

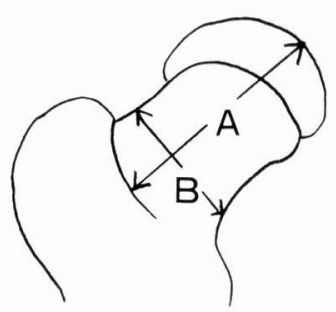

Head-neck index $=\frac{\mathrm{A}}{\mathrm{B}}$

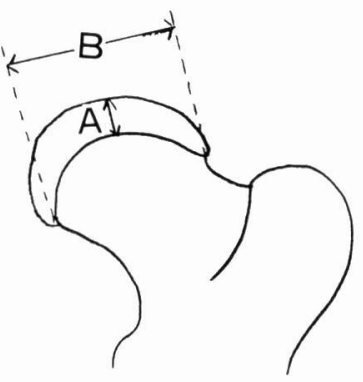

Epiphyseal index $=\frac{\mathrm{A}}{\mathrm{B}}$

Fig. 9

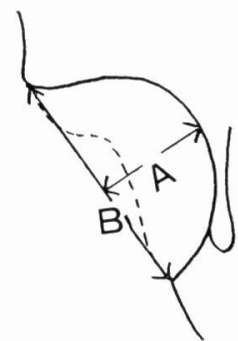

Acetabular index $=\begin{aligned} & \mathrm{A} \\
& \mathrm{B}\end{aligned}$ 
TABLE 2

\begin{tabular}{c|c|c|c|c}
\hline $\begin{array}{c}\text { Method of } \\
\text { treatment }\end{array}$ & Hips & Head-neck index & Epiphyseal index & Acetabular index \\
\hline \multirow{2}{*}{ Lorenz } & Dislocated side 44 & $155.67 \pm 34.09$ & $33.19 \pm 7.33$ & $29.55 \pm 4.70$ \\
& Healthy side 22 & $173.36 \pm 19.91$ & $41.64 \pm 7.82$ & $31.88 \pm 3.38$ \\
\hline \multirow{2}{*}{$\begin{array}{c}\text { Abducter } \\
\text { splint }\end{array}$} & Dislocated side 67 & $163.07 \pm 31.56$ & $33.75 \pm 6.56$ & $31.17 \pm 4.65$ \\
& Healthy side 21 & $174.96 \pm 21.13$ & $40.74 \pm 6.57$ & $32.32 \pm 2.22$ \\
\hline
\end{tabular}

Schildhauer (1974) reported on avascular necrosis as follows: "The incidence of avascular necrosis of the femoral head depends on the degree of dislocation and on the degree of abduction-trauma".

The incidence of avascular necrosis is in 4 cases ( 5.48 per cent) of 73 cases in Pavlik's group. The injury of metaphysis less occurred and epiphysitis doesn't result in serious deformity of the femoral head and neck (Figs. 7 and $8)$.

\section{The late results of the Lorenz method and the abducter splint}

The results were expressed as the epiphyseal index, head-neck index and acetabular index following HeymanHerndon's method (Fig. 9).

The comparisons yielded the data shown in Table 2. It can be seen that in each value Lorenz's group had somewhat lower levels. But the dislocated hip shows remarkably wrong values than that of each healthy side, especially head-neck index and epiphyseal index.

This is clearly that the epiphysis and metaphysis of the femur are injured by these treatment. Trueta (1957) observed the normal vascular supply of the human femoral head during growth: ............ "during from four months to four years the predominant blood flow arise from the metaphyseal vessels crossing the area later to be occupied by the growth plate". So it is proved the injury of the metaphyseal vessels during the first year of life resulted in avascular necrosis and the residual deformity.

\section{The results of conservative treatment}

As indicated in Table 3 satisfactory results were obtained only in 29.5 per cent in the Lorenz method and 38.8 per cent in the abducter splint. In the Pavlik method the deformities of the femoral head and neck are few, so that the results are satisfactory in 79.4 per cent. Avascular necrosis and the severe deformity are seldom occurred in this method. Thus, it is clear that how excellent the active functional treatment is. The patient is allowed to exercise the lower extremities except the extension of the hips, so the adductor muscles are loosed gradually and spontaneous reduction has been done in this functional treatment. Whereas in the Lorenz method the patient was performed the manual reduction and immobilized in the Lorenz position for long time. The patient in the abducter splint was impelled and immobilized in the Lorenz position, too. As a result of immobilization, continuous compression of the cartilage between the femoral head and the acetabulum and tight adductor muscles in extreme abduction, which cause of severe avascular necrosis. Then avascular necrosis following these treat- 
TABLE 3

\begin{tabular}{|c|c|c|c|c|c|c|c|c|c|c|}
\hline $\begin{array}{l}\text { Method } \\
\text { of } \\
\text { treatment }\end{array}$ & $\begin{array}{c}\text { Mean period } \\
\text { of } \\
\text { follow-up }\end{array}$ & Hips & $\begin{array}{r}\text { Well } \\
\text { hi }\end{array}$ & $\begin{array}{l}\text { veloped } \\
\text { joint }\end{array}$ & $\begin{array}{l}\text { Sligh } \\
\text { mity } \\
\text { head }\end{array}$ & $\begin{array}{l}\text { defor- } \\
\text { f the } \\
\text { nd neck }\end{array}$ & $\begin{array}{l}\text { Mod } \\
\text { seve } \\
\text { mity } \\
\text { head }\end{array}$ & $\begin{array}{l}\text { te or } \\
\text { defor- } \\
\text { f the } \\
\text { ad neck }\end{array}$ & $\begin{array}{l}\text { Dys } \\
\text { acet } \\
\text { (abo }\end{array}$ & $\begin{array}{l}\text { asia of } \\
\text { ulum } \\
26 \\
\text { grees) }\end{array}$ \\
\hline \multirow[b]{2}{*}{ Lorenz } & \multirow[b]{2}{*}{11.3 years } & \multirow[b]{2}{*}{44} & \multicolumn{2}{|c|}{ No. Per cent } & \multicolumn{2}{|c|}{ No. Per cent } & \multicolumn{2}{|c|}{ No. Pẹr cent } & \multicolumn{2}{|c|}{ No. Per cent } \\
\hline & & & 13 & 29.5 & 15 & 34.0 & 16 & 36.3 & 9 & 20.5 \\
\hline $\begin{array}{l}\text { Abducter } \\
\text { splint }\end{array}$ & 12 years & 67 & 26 & 38.8 & 20 & 29.8 & 21 & 31.3 & 11 & 16.4 \\
\hline $\begin{array}{c}\text { Pavlik } \\
\text { splint }\end{array}$ & 6.1 years & 73 & 59 & 79.4 & 2 & 2.7 & 3 & 4.1 & 9 & 12.3 \\
\hline
\end{tabular}

TABLE 4

Moderate or severe deformity of the head and neck

\begin{tabular}{|c|c|c|c|c|c|}
\hline $\begin{array}{l}\text { Method of } \\
\text { treatment }\end{array}$ & $\begin{array}{l}\text { Mean period } \\
\text { of } \\
\text { follow-up }\end{array}$ & Hips & $\begin{array}{l}\text { Elevation of } \\
\text { trochanter }\end{array}$ & Coxa vara & Coxa valga \\
\hline & & & No. Per cent & No. Per cent & No. Per cent \\
\hline Lorenz & 11.3 years & 44 & 20.5 & 9.1 & 15.9 \\
\hline Abducter splint & 12 years & 67 & 11.9 & 22.4 & 5.9 \\
\hline Pavlik splint & 6.1 years & 73 & 0 & 0 & 0 \\
\hline
\end{tabular}

ment lead to the severe deformities of the femoral head and neck, such as elevation of the trochanter (Table 4). Komiyama (1976) reported the incidence of osteoarthritis was in 31.7 per cent of 60 cases by the abducter splint. As for dysplasia of the acetabulm there are comparatively more (12.3 per cent) in the Pavlik method. But the cases treated by the Pavlik splint are followed up only 6.1 years. The dysplasia above 30 degrees are two cases and the remains are slight dysplasia, so it may be that the dysplasia is improved gradually. The possibility is studied next section.

The results of the Pavlik method

The results of the cases treated by the Pavlik splint are given in Table 5 .

TABLE 5

\begin{tabular}{c|c|c|c|c|c}
\hline Hips & $\begin{array}{c}\text { Mean period } \\
\text { of follow-up }\end{array}$ & $\begin{array}{c}\text { Acetabular } \\
\text { angle } \\
\text { (degrees) }\end{array}$ & CE angle & $\begin{array}{c}\text { Collo-diaphyseal } \\
\text { angle }\end{array}$ & $\begin{array}{c}\text { Antetorsional } \\
\text { angle }\end{array}$ \\
\hline 73 & 3 years & $23.67 \pm 4.60$ & $18.70 \pm 7.16$ & $140.90 \pm 7.84$ & $39.42 \pm 12.92$ \\
\hline 73 & 6.1 years & $20.69 \pm 4.23$ & $21.63 \pm 5.04$ & $140.21 \pm 6.74$ & $33.43 \pm 11.15$ \\
\hline
\end{tabular}


The relationship between the head and the acetabulum was expressed as the CE angle (Wiberg, 1939). The antetorsional angle was measured by Kai's method (1939). The hip joint followed up over 5 years was compared with the early results. It is clear from these data that the mean antetorsion decreases by 6 degrees, while the collo-diaphyseal angle is minimal or no change. The mean acetabular angle develops from 23.7 to 20.7 degrees. According to $\mathrm{Kai}$, the mean value of antetorsional angle was 33.1 degrees and collo-diaphyseal angle 134.8 degrees in normal children from a half to 4.1 years. Chen (1971) investigated the acetabular angle in normal children. In his study the mean acetabular angle was 26.6 degrees in women and 24.6 degrees in men in the first year of life. It developed to about 23 degrees in the second year and 20 degrees in the sixth year of life. In my results the mean value of antetorsion and acetabulm show to approximate normal value. As the antetorsion and acetabulum are improved, the head is covered well by the acetabulum and the $\mathrm{CE}$ angle is above 21 degrees.

\section{DISCUSSION}

Functional treatment of congenital dislocation of the hip in infancy has proved excellent without compare as mentioned above. Then I mention about the Pavlik method. In our experience (Yano, 1971) spontaneous reduction was obtained in 85 per cent in the Pavlik method. The value of 85 per cent coincides closely with the 84.08 per cent reported by Pavlik. The reported percentage of spontaneous reduction has ranged from 81 per cent (Oda, 1968) to 95 per cent (Akasaka, 1969).

Mittelmeier (1961) analysed mechanically how to reduce the dislocated hip in the Pavlik method. The hip in 90 degrees of flexion is led to abduction by the patient pressing down the splint and the adductor muscles are loosed gradually. The function of the gluteus maximus in flexion of the hip press the trochanter to posterior. The function of the muscle of quadriceps shows in $S$. It acts as rebound $R$ by the patient pressing down the splint. The power of $\mathrm{R}$ leads the femoral head in the direction of concentration $\mathrm{E}$ (Fig. 10).

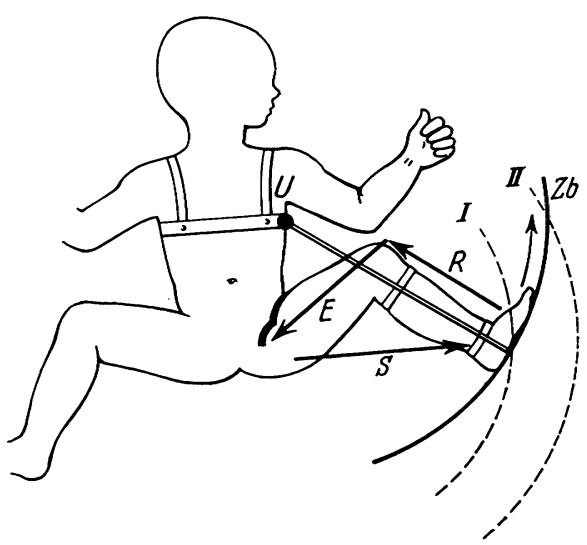

Fig. 10 from Mittelmeier (1961)
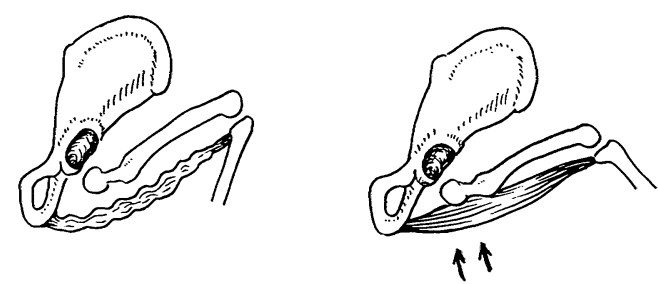

Fig. 11 from SAKaGUCHI (1971)

Sakaguchi (1971) has valued much the function of the hamstrings as an elastic splint and attended to extension of the knee (Fig. 11).

Sakaguchi (1973) has stated that the functional treatment changed not only 
the method of treatment but approach to congenital dislocation of the hip. $\mathrm{He}$ has explained the reduced hip by manipulation needs fixation but the reduced hip by spontaneous reduction does not easily dislocate without fixation. He has used a Pavlik splint even if spontaneous reduction could not be obtained, as a preparation for manipulation. As a result of loosening of adductor muscles by Pavlik splint, the reduction by manipulation is easily done and avascular necrosis never occurs.

In my study the incidence of avascular necrosis ( 5.48 per cent) following the Pavlik method is considerably high compared with another authors. The reported incidence of avascular necrosis varies from 0 to 7.6 per cent : Pavlik (1958) 0 ; Suzuki (1971) 1.3 per cent; Nakamura (1965) 2.2 per cent; Oda (1974) 4.7 per cent; author 5.48 per cent ; Hasegawa (1970) 7.6 per cent. For criteria of avascular necrosis I used not only Perthes-like change but slight degrees of epiphysitis. In my experience avascular necrosis occurred in the cases which the splint is applied too tightly. As Pavlik mentioned the splint should be applied loosely. When spontaneous reduction has not been done in a week or two, the hip is flexed over 90 degrees but it is not too strongly. I think after the spontaneous reduction has been done, the hip should be maintained in 90 degrees of flexion again. Moreover, if the dorsal belts are applied tightly, the patient is impelled the Lorenz position. Dörr (1966) explained that the splint had to be applied loosely so that the pain and stimulation were not induced in the hip by the weight of the lower extremity. It is clear from these data that diminishing of avascular necrosis is the most important.

As for beginning of the treatment, I consider that it is suitable from about 3 months of infants, who grow fairly and move extremities actively, though avascular necrosis does not occur in 3 month-old-infant in the Pavlik splint.

\section{ACKNOWLEDGEMENT}

I wish to express my thanks to Dr. Prof. S. Miyagi and Dr. Assisit. Prof. Yano for their direction and other members of orthopedic department.

\section{REFERENCES}

AKasAKA, K. (1969). Treatment of congenital dislocation of the hip by Pavlik splint. Clinical Orthopedic Surgery, 4, 180-187.

Becker, F. (1963). Prophylaxe und Frühbehandlung der kongenitalen Dyslasie des Hüftgelenks. Arch. orthop. Unfall-chir., 55, 218-229.

Becker, F. : Cited by LAnge, M. (1971). Lehrbuch der Orthopadie und Traumatologie, Bd. 1, Ferdinand Enke Verlag Stuttgart, 436-438.

Chen, S. H. and Yamamuro, T. (1971). Radiological study on the development of normal hip joint in early infancy. Cent. Jap. J. Orthop. Traumat., 14, 269-272.

DöRR, W. M. (1965). Erfahrungen mit dem Riemenbügel nach Pavlik in Behandlung der sog. angeborenen Hüftgelenksluxation und ihrer Vorstuben. Z. Orthop., 101, 535-545.

GAGE, J. R. and WINTER, R. B. (1972). Avascular necrosis of the capital femoral epiphysis as a complication of closed reduction of congenital dislocation of the hip. J. Bone and Joint Surg., 54-A, 373-388.

HasegawA, K. (1970). Deformity of the femoral head after the non-operative treatment of the femoral congenital dislocation of the hip. J. Nigata M. A., 34, 281-292.

Heyman, C. H. and Herndon, C. H. (1950). Legg-Perthes disease: A method for the measurement of the roentgenographic result. J. Bone and Joint Surg., 32-A, 767-778.

Hyakutake, S. and Sakai, H. (1956). End results of closed reduction in congenital dislocation of the hip. Orthopedic Surgery, 7, 94-98.

KAI, M. (1937). A method for the radiological 
measurement of the proximal part of the femur and its clinical application. J. Jap. Orthop. Ass., 12, 389-409 and 448-497.

Komiyama, Y. (1976). Long-term results of conservative treatment of congenital dislocation of the hip with special reference to the Sudare divaricating splint. J. Jap. Orthop. Ass., 50, 325-341.

LAGrange, J. and Dunover, J. (1962). La vascularisation de la tête femorale de l'enfent. Revue d'orthopédie, 48, 123-137.

Lange, M. (1929): Cited by Severin, E. (1941). Congenital dislocation of the hip joint. Acta Chir. Scand., 84, Suppl. 63, 18-19.

LORENZ, A. (1920). Die sogenante angeborene Hüftverrenkung ihre Pathologie und Therapie. Stuttgart.

Mittelmeier, H. (1961). Beitrag zur funkutionellen Therapie und Spontanreposition der angeborenen Luxationshüfte mit $\mathrm{Sp}$ reizhöschen und Pavlikbandage. Arch. orthop. Unfall-chir, 52, 465-522.

Nakamura, S., Oosawa, K., Ikeda, H., Mizota, T., Oda, T., Ooe, S., Umegae, K., Enomoto, T. and Kobayashi, T. (1965). Experience of treatment of congenital dislocation of the hip in infant. Orthopedic Surgery, 16, 770774.

Oda, K., Matsui, S., Hirata, H. Iwanaga, H. and Mizobe, Y. (1969). Treatment of congenital dislocation of the hip by Pavlik splint. Clinical Orthopedic Surgery, 4, 180187.

Oda, K., Hattori, S., Goto, T., Senzoku, F. and IMAGAMA, T. (1974). Result of treatment by the Pavlik method. J. Jap. Orthop. Ass., 48, 792-793.

PAVliK, A. (1958). Die funktionelle Behandlungs methode mittels Riemenbügel als Prinzip der konservativen Therapie bei angeborenen Hüftgelenksverrenkungen der Säugling. Z. Orthop., 89, 341-352.

SAKAGUCHI, R. (1970). Protective reduction of congenital dislocation of the hip. Orthopedic Surgery, 21, 521.
SAKAGUCHI, R. (1971). Practice of treatment of congenital dislocation of the hip in infancy. Kanehara, Tokyo.

SAKAGUCHI, R. (1973). My thought and suggestion about reduction. Orthopedic Surgery, special edition of treatment of congenital dislocation of the hip. 24, 529-530.

Salter, K. B. Kostuik, J. and Dallas, S. (1969). Avascular necrosis of the femoral head as a complication of treatment for congenital dislocation of the hip in young children : a clinical and experimental investigation. Canad. J. Surg., 12, 44-61.

Schildhauer, M., Schumann, B. T. and Tönnis, D. (1974). Untersuchungen zur Verringerung der Hüftkopfnekroserate bei der Behandlung der angeborenen Hüftgelenksverrenkung. Z. Orthop. 112, 283-293.

Senju, F. (1960). Early detection of the congenital dislocation of the hip joint and its countermeasure. J. Kurume Med. Assoc., 23, 3979-4006.

Suzuki, R., Kabata, K. and Azuma,A. (1961). Experience of treatment of congenital dislocation of the hip with the Pavlik splint. Orthopedic Surgery, 12, 1148-1152.

Suzuki, R. (1971). Congenital dislocation of the hip and functional treatment of it. Nankodo, Tokyo.

Trueta, J. (1957). The normal vascular anatomy of the human femoral head during growth. J. Bone and Joint Surg., 39-B, 358-394.

Tucker, F. R. (1949). Arterial supply at the femoral head and its clinical importance. J. Bone and Joint Surg., 31-B, 82-93.

WIBERG, G. (1939). Studies on dysplastic acetabula and congenital subluxation of the hip joint. Acta Chir. Scand. Suppl, 58.

Yano, T., Mita, M., OKuno, T. and Hashikawa, T. (1971). Treatment of infantile congenital dislocation of the hip with Pavlik's splint. J. West Jap. Orthop. Traum., 20, 237-239. 